\title{
Uma Proposta de Abordagem Pedagógica para o Uso do RPG Maker no Ensino de Cartografia
}

\author{
Carlos Souza $^{1}$, Enio Monteiro ${ }^{1}$, Carlos Portela ${ }^{1}$ \\ ${ }^{1}$ Faculdade de Sistemas de Informação (FASI) - Universidade Federal do Pará (UFPA) \\ Cametá - PA - Brasil \\ \{carlosalexandre03, eniojpmonteiro\}@hotmail.com, csp@ufpa.br
}

\begin{abstract}
The use of Digital Educational Games (DEG) has been gaining more space in the classroom and can become a viable alternative, for example, in Geography teaching. However, for the DEG use to meet the objectives expected by the teacher, the teaching approach should be planned. In this context, this paper proposes a pedagogical approach, having as theoretical support the constructionism and as technical support the RPG Maker software. This approach aims to assist in the teaching-learning process of School Cartography in Primary Education II. The proposal was applied and evaluated by professors and students of the Geography course at <omitted to review>. From the results of this application, it was concluded that the adoption of this proposal made the class more interesting, contextualized and facilitated the learning of the Cartography contents.
\end{abstract}

Resumo. A utilização de Jogos Educativos Digitais (JEDs) vêm ganhando cada vez mais espaço em sala de aula e pode se tornar uma alternativa viável, por exemplo, no ensino de Geografia. No entanto, para que o uso de JEDs atenda aos objetivos esperados pelo docente, deve-se planejar a abordagem de ensino. Nesse contexto, este artigo propõe uma abordagem pedagógica, tendo como suporte teórico o construcionismo e como suporte técnico o software RPG Maker. Essa abordagem visa auxiliar no processo de ensinoaprendizagem da Cartografia Escolar no âmbito do Ensino Fundamental II. A proposta foi aplicada e avaliada por professores e alunos do curso de Geografia da UFPA Campus Cametá. A partir dos resultados dessa aplicação, concluiu-se que a adoção dessa proposta tornou a aula mais interessante, contextualizada e facilitou a aprendizagem dos conteúdos relacionados à Cartografia.

\section{Introdução}

A tecnologia, aos longos dos anos, vem ganhando cada vez mais espaço na vida dos alunos e, consequentemente, em sala de aula. Todo esse contato, existente entre alunos e os meios tecnológicos, acaba por demandar que os docentes usem a diversidade para elaborar um senso de construcionismo mais rico e multifacetado, e muito mais profundo em suas implicações [Papert 2008]. Filho et al. (2015) afirmam que se o professor não procurar acompanhar este avanço, ele ficará com sua metodologia ultrapassada, pois os alunos ficarão desmotivados se o professor não preparar uma aula que tenha como ferramenta essas novas tecnologias. 
VIII Congresso Brasileiro de Informática na Educação (CBIE 2019)

Anais do XXV Workshop de Informática na Escola (WIE 2019)

Nesse contexto, Neto et al. (2013) afirmam que a utilização de Jogos Eletrônicos Digitais (JEDs) no âmbito escolar pode se tornar uma alternativa viável, por exemplo, no ensino de Geografia. Conforme afirma Gaite (1995), o geógrafo não consegue reproduzir no laboratório os fatos e fenômenos que estuda, e sim, o reproduzem recorrendo à simulação ou a jogos. Isso permite abordar com simplicidade certos temas de caráter complexo, sendo estas ferramentas adequadas ao processo de ensinoaprendizagem.

Para a construção desta abordagem visual do ensino cartográfico, observa-se a possibilidade de adoção do software construtor de jogos RPG Maker. Esta ferramenta permite a criação de cenários (mapas) de forma simples, pois oferece uma base de dados contendo diversos componentes prontos como: florestas, montanhas, lagos, casas, edifícios, paredes, entre outras [Aragão, Dias e Fernandes 2016]. No entanto, para que o uso de JEDs atenda aos objetivos esperados pelo docente, deve-se especificar claramente o que ensinar e, também, a forma de ensinar deve ser planejada [Fernandes, Aranha e Lucena 2018].

Alguns autores relatam a adoção desta ferramenta em sala de aula. Paula et al. (2015) adotaram o RPG Maker como um objeto de aprendizagem para o ensino de química ambiental. Rosa e Maltempi (2003) adotaram o software RPG Maker como uma possibilidade de uso na Educação Matemática. Já Sousa e Serafim (2016) utilizaram a ferramenta para o ensino da Ditadura Militar no Brasil. Porém, estes não tratam do ensino de Geografia e nem explicitam o uso de uma teoria de ensino.

Nesse contexto, capacitar o docente na utilização de JEDs, alinhado a Teoria do Construcionismo [Papert 2008], pode ser o fator contribuinte para que os alunos se tornem mais motivados em sala de aula. De maneira complementar, deve-se orientar os alunos para que as informações obtidas do uso dessa tecnologia se tornem significativas para a construção do conhecimento. Assim, este artigo propõe uma abordagem pedagógica, tendo como suporte teórico o construcionismo e como suporte técnico o software RPG Maker. Essa abordagem visa auxiliar no processo de ensinoaprendizagem da Cartografia Escolar no âmbito do Ensino Fundamental II.

Além desta seção introdutória, na Seção 2 são abordados os métodos utilizados na pesquisa, tanto para definição quanto para avaliação da abordagem proposta. Já na Seção 3 é descrita a abordagem pedagógica, bem como suas etapas para inserção do RPG Maker como ferramenta de ensino. A Seção 4 mostra o processo de aplicação e avaliação desta proposta por professores e alunos do curso de Geografia da UFPA Campus Cametá. Por fim, a Seção 5 apresenta as conclusões do artigo, além de destacar as próximas etapas a serem realizadas.

\section{Métodos}

Esta pesquisa optou por realizar uma pesquisa bibliográfica do tipo exploratória, tendo como objetivo buscar compreender alguns conceitos a respeito do tema e da problemática. A etapa seguinte consistiu na sua avaliação baseada no método empírico Pesquisa-Ação [Easterbrook et al. 2007], para inteirar-se como os docentes em formação são apresentados e capacitados para a utilização de JEDs no âmbito escolar. 
VIII Congresso Brasileiro de Informática na Educação (CBIE 2019)

Anais do XXV Workshop de Informática na Escola (WIE 2019)

Após o levantamento dos dados preliminares criou-se uma abordagem para a capacitação dos professores na utilização de JEDs, sendo esta constituída de 5 (cinco) etapas: i) Capacitação dos professores; ii) Planejamento da aplicação de JEDs em sala de aula; iii) Aplicação em sala de aula; iv) Avaliação dos resultados; e v) Atualização da abordagem.

Como meio de validar a abordagem, realizou-se um caso de estudo aplicado na Geografia, mais especificamente no conteúdo de Cartografia, uma vez que, trata-se de uma disciplina bastante descritiva e que necessita de uma abordagem mais visual.

Realizou-se uma apresentação dessa proposta de abordagem para 6 (seis) especialistas de Geografia analisarem o seu conteúdo e etapas. Após essa análise, iniciou-se a capacitação desses especialistas, a qual foi realizada no Laboratório de Informática da UFPA Campus Cametá, para a explanação da Teoria do Construcionismo e como utilizá-la na incorporação de JEDs no âmbito educacional. Adicionalmente, os especialistas aplicaram a abordagem em sala de aula para 5 (cinco) alunos a fim de avaliá-la.

Por fim, realizaram-se entrevistas com os professores e alunos para a validação da pesquisa e analisou-se qualitativamente a utilização dessa abordagem para a inclusão de JEDs em sala de aula.

\section{Abordagem Proposta}

Existe uma grande problemática quanto à alfabetização cartográfica, como debatido por Santos et al. (2011) e, consequentemente, surge a necessidade de uma abordagem mais visual desse conteúdo. A fim de encontrar uma forma de relacionar o conteúdo abordado ao ambiente em que o aluno está inserido, e obter um resultado satisfatório quanto ao ensino cartográfico, propõe-se uma abordagem que se utiliza da teoria do construcionismo proposta por Papert (2008) e do software RPG Maker. Espera-se, através dessa abordagem, demonstrar que a união de ambos pode ser o diferencial para aproximar professores e alunos em uma vivência empírica do conteúdo outrora abordado de forma descritiva em sala de aula.

Diante disso, a aplicação dessa abordagem será baseada na pesquisa de Sousa e Serafim (2016), onde o processo é abordado em quatro estágios. Contudo, será dado ênfase na qualificação dos docentes para a utilização adequada da ferramenta e também no acompanhamento durante a aplicação da abordagem proposta em sala de aula.

\subsection{Público-Alvo}

De acordo com Filho et al. (2015), o professor deve utilizar o computador como uma ferramenta que o auxilie nas suas diversas atividades como docente. Desta forma, o professor não seria mais visto como apenas um "entregador" do conhecimento, mas sim como um facilitador; enquanto o estudante deixaria de ser passivo, para ter um papel ativo no desenvolvimento do seu conhecimento.

Portanto, o professor, por possui um papel primordial e ser visto como o mediador do processo de ensino-aprendizagem, necessita estar capacitado no uso de novas tecnologias, e possuir uma metodologia adequada para a utilização dessas em sala 
VIII Congresso Brasileiro de Informática na Educação (CBIE 2019)

Anais do XXV Workshop de Informática na Escola (WIE 2019)

de aula [Silva et al. 2016]. E assim, ele deve encontrar meios que motivem e interessem aos alunos, para que esses participem do processo de forma mais efetiva e prazerosa.

A cartografia escolar possui características distintas para os diversos anos do ensino fundamental e médio. E em conformidade com as diretrizes da Base Nacional Comum Curricular (BNCC) [MEC 2018], essa abordagem define como público-alvo os professores de Geografia do Ensino Fundamental II, tendo em vista que, é no terceiro ciclo da educação básica (a partir do $6^{\circ}$ ano) que se inicia a formação dos alunos nos elementos da representação gráfica do espaço geográfico.

\subsection{Etapas da Abordagem}

A Figura 1 representa o ciclo de vida interativo da abordagem proposta. Este ciclo é composto pelas cinco etapas descritas nas subseções seguintes.

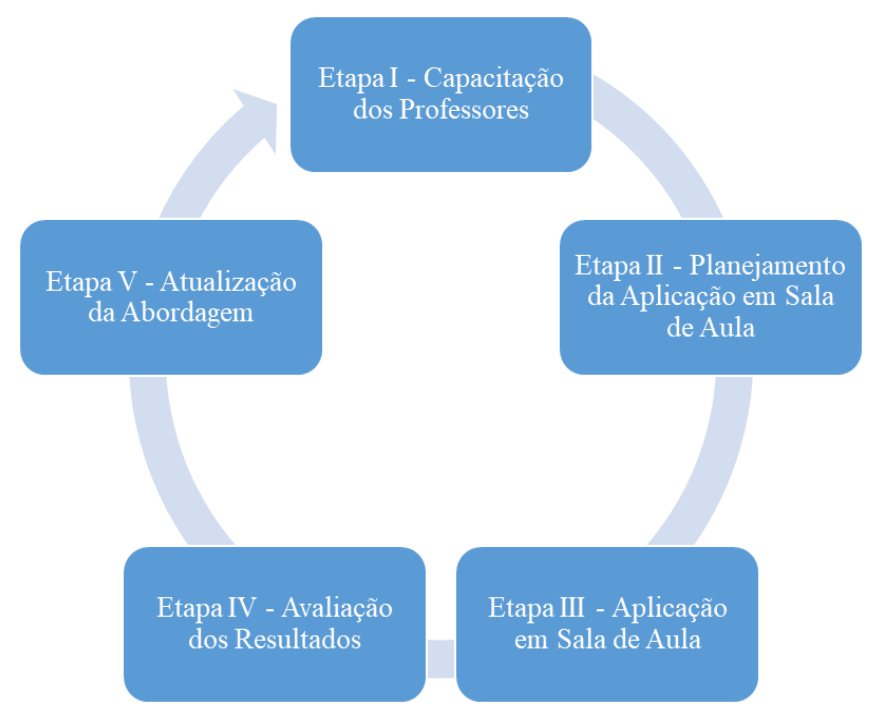

Figura 1. Etapas da Abordagem Proposta.

\subsubsection{Etapa I - Capacitação dos Professores}

A primeira etapa consiste na capacitação dos professores em formação no uso de jogos e da ferramenta RPG Maker. Nessa etapa, deve-se focar na preparação do professor, de modo a apresentá-lo à ferramenta utilizada no processo de criação do JED. Recomendase a realização de uma oficina de capacitação aos docentes em formação do curso de Licenciatura em Geografia. Assim, deve-se abordar o uso de jogos em sala de aula e apresentar a proposta de utilização do software RPG Maker como uma ferramenta educacional, apresentando-se os seus recursos básicos.

\subsubsection{Etapa II - Planejamento da Aplicação em Sala de Aula}

A etapa II consiste no Planejamento da Aplicação do recurso tecnológico em sala de aula. É nessa etapa que deve ser planejado, junto ao professor, como se dará a aplicação do software RPG Maker em sala de aula. Definindo-se qual a temática (Cartografia) e a leitura bibliográfica, quantidade de aulas necessárias, a viabilidade, e a melhor estratégia para abordagem da mesma. Essa etapa não envolve diretamente os alunos, mas sim, um planejamento prévio a respeito do que seria desenvolvido durante as aulas, e a elaboração de algumas apresentações (slides) sobre a ferramenta. 
VIII Congresso Brasileiro de Informática na Educação (CBIE 2019)

Anais do XXV Workshop de Informática na Escola (WIE 2019)

\subsubsection{Etapa III - Aplicação em Sala de Aula}

A etapa III deve ser realizada na sala de aula, mas, antes que essa ocorra, recomenda-se a realização de uma pesquisa pré-disciplina com os alunos a fim de se identificar o conhecimento prévio desses a respeito do conteúdo a ser ministrado, e também, se os mesmos possuem o conhecimento a respeito da existência e utilização de softwares como ferramenta educacional. Após a realização da pesquisa, deve-se apresentar aos alunos em formação o software RPG Maker por meio das apresentações produzidas no estágio anterior. Desse modo, os alunos terão um primeiro contato com a ferramenta, e assim, espera-se despertar suas curiosidades e o interesse em descobrir como esse software será utilizado em suas aulas.

Após a apresentação do software aos alunos, deve-se iniciar a construção de um cenário (mapa), baseado no planejamento pedagógico realizado na etapa II. Para a construção do mapa, utilizar-se-ão as noções básicas da alfabetização cartográfica (linhas, pontos e áreas), visão (horizontal/lateral e vertical), dimensão (somente bidimensional (2D), uma vez que, o software não contempla a modelagem tridimensional (3D)), orientação e escala. Destaca-se que esses recursos fazem parte das funcionalidades básicas da ferramenta.

\subsubsection{Etapa IV-Avaliação dos Resultados}

A última etapa deve ser reservada para a aplicação de um questionário pós-aula aos alunos, para que esses possam responder se houve uma melhora em seus conhecimentos, e consequentemente, relatem suas experiências e as dificuldades encontradas nessa atividade pedagógica. Os professores também devem avaliar a proposta, podendo contribuir significativamente para a abordagem proposta como uma ferramenta de apoio ao ensino de Geografia.

Tal avaliação se faz necessária para que seja realizada uma análise quantitativa, a fim de identificar a opinião dos docentes e alunos quanto à real aceitação de JEDs como ferramenta educacional. Assim, pode-se validar o conjunto das etapas e os resultados obtidos com a utilização da proposta pedagógica aliada ao uso da ferramenta RPG Maker em sala de aula. Também deve-se realizar uma análise qualitativa, para que seja feita a melhoria continua da proposta, e assim, não deixar que se torne obsoleta.

\subsubsection{Etapa V-Atualização da Abordagem}

Por fim, na fase de Atualização da Abordagem, o professor pode colaborar com um feedback do uso da abordagem, apresentando os pontos fortes e fracos, e sugerindo opções de melhorias. Assim, espera-se que a proposta se mantenha atualizada, a partir da implementação das melhorias, e cresça de maneira colaborativa com as contribuições dos seus usuários.

\subsection{Aplicação da Abordagem}

A fim de que essa abordagem atinja o seu objetivo, faz-se necessário requisitos mínimos para aplicá-la em sala de aula. Entre os requisitos necessários, encontram-se a capacitação do docente, uma vez que, esse terá o papel de orientar os alunos na 
VIII Congresso Brasileiro de Informática na Educação (CBIE 2019)

Anais do XXV Workshop de Informática na Escola (WIE 2019)

utilização da ferramenta. Além disso, o professor deverá possui um plano de aula referente a disciplina que será ministrada. Esse plano de aula, deve também, explicitar claramente como se dará a abordagem de utilização da ferramenta durante a aula.

Para que seja possível a instalação e utilização da ferramenta por parte do docente, faz-se necessário que ele possua os seguintes materiais:

- Setup de instalação: executável que contém todos os arquivos necessários para que o programa possa ser instalado no computador do usuário;

- Manual de instalação: é o documento que contém todos os passo-a-passos e requisitos necessários para que seja possível realizar a instalação da ferramenta de maneira correta;

- Manual de usuário: documento que contém as instruções necessárias para que o usuário seja capaz de utilizar a ferramenta;

Outro documento de suma importância para essa abordagem é o material de apoio (apresentação em slide), visto que, é através desse material que os alunos serão apresentados à ferramenta. Todos os requisitos descritos anteriormente encontram-se disponíveis em lafoca.com.br/rpgmaker.

\section{Avaliação da Proposta}

A abordagem foi aplicada através de um teste que simulou uma aula de Geografia, no qual participaram 3 (três) alunas em formação e 3 (três) professores do Curso de Licenciatura em Geografia ofertado pela UFPA Campus Cametá. Utilizou-se um questionário contendo perguntas abertas e fechadas descritas nas subseções a seguir.

Esse teste de aplicação ocorreu no dia 01 de novembro de 2018 nas dependências do Laboratório de Informática da UFPA Campus Cametá. Os dados analisados são apresentados nas subseções seguintes.

\subsection{Sobre a Etapa I}

Os avaliadores foram previamente capacitados para que pudessem validar esta proposta de abordagem. O Quadro 1 apresenta uma síntese dos pontos fortes e fracos da etapa I da proposta.

Quadro 1. Considerações Gerais sobre a Etapa I.

\begin{tabular}{l|l}
\hline \multicolumn{1}{c|}{ Pontos Fortes } & \multicolumn{1}{c}{ Pontos Fracos } \\
\hline $\begin{array}{l}\text { O esclarecimento sobre o jogo e seu potencial } \\
\text { pedagógico para o ensino de Geografia. }\end{array}$ & $\begin{array}{l}\text { Faltou um esclarecimento maior sobre o jogo } \\
\text { enquanto ferramenta didática. }\end{array}$ \\
\hline
\end{tabular}

\subsection{Sobre a Etapa II}

Para a validação desta etapa, os avaliadores reuniram-se para dialogar, planejar e definir o plano de aula que foi utilizado durante a Etapa III e também elaborar uma ficha avaliativa pré e pós aula.

Assim, o plano de aula elaborado aborda como temática a Geografia Urbana, assunto ministrado durante o Ensino Fundamental II ( $6^{\circ}$ ao $9^{\circ}$ ano). E foi constituído de maneira a alinhar o conteúdo abordado ao RPG Maker, e assim, poder explorar a 
VIII Congresso Brasileiro de Informática na Educação (CBIE 2019)

Anais do XXV Workshop de Informática na Escola (WIE 2019)

ferramenta ao máximo para averiguar se os alunos compreenderam o conteúdo teórico ministrado em sala de aula.

Já a ficha avaliativa foi composta por 6 questões, sendo 2 sobre a abordagem proposta, a fim de validá-la com os alunos, uma vez que, a mesma já foi avaliada por especialista. As 4 questões restantes foram referentes a temática abordada no plano de aula, para averiguar se houver melhora no aprendizado dos participantes.

\subsection{Sobre a Etapa III}

Esta etapa deveria ocorrer em sala de aula, no entanto, devido ao período de abordagem do conteúdo cartográfico no calendário escolar 2018 da rede pública municipal de Cametá já ter finalizado. E também, o período de estágio de docência do ano de 2018 do curso de licenciatura em Geografia da UFPA já ter encerrado. Assim, realizou-se a avaliação desta etapa no Laboratório de Informática da universidade.

Destaca-se que o experimento foi realizado com apenas 5 (cinco) alunos de graduação. Enfatiza-se que todos os participantes selecionados eram calouros de 2018, pois estes são alunos que há pouco tempo se formaram no ensino médio. E por questões de confidencialidade, os nomes dos participantes serão omitidos, sendo esses tratados neste texto de forma anônima.

Nesta etapa, utilizou-se uma ficha avaliativa pré e pós aula, contendo perguntas abertas e fechadas, ambos elaborados na Etapa II. Utilizou-se esta metodologia avaliativa para identificar o conhecimento prévio dos envolvidos a respeito do assunto, e também, como ferramenta exploratória quanto à utilização de JEDs durante as aulas em sala de aula.

$\mathrm{Na}$ busca por instigar os alunos na participação da oficina, adotou-se como meio de incentivo, premiar com 1 (um) pendrive o aluno que construísse um mapa no RPG Maker contendo o maior número de serviços públicos e privados ofertados ao redor da praça da cultura na Cidade de Cametá. A Figura 2 representa um mapa construído por um aluno utilizando o software RPG Maker.

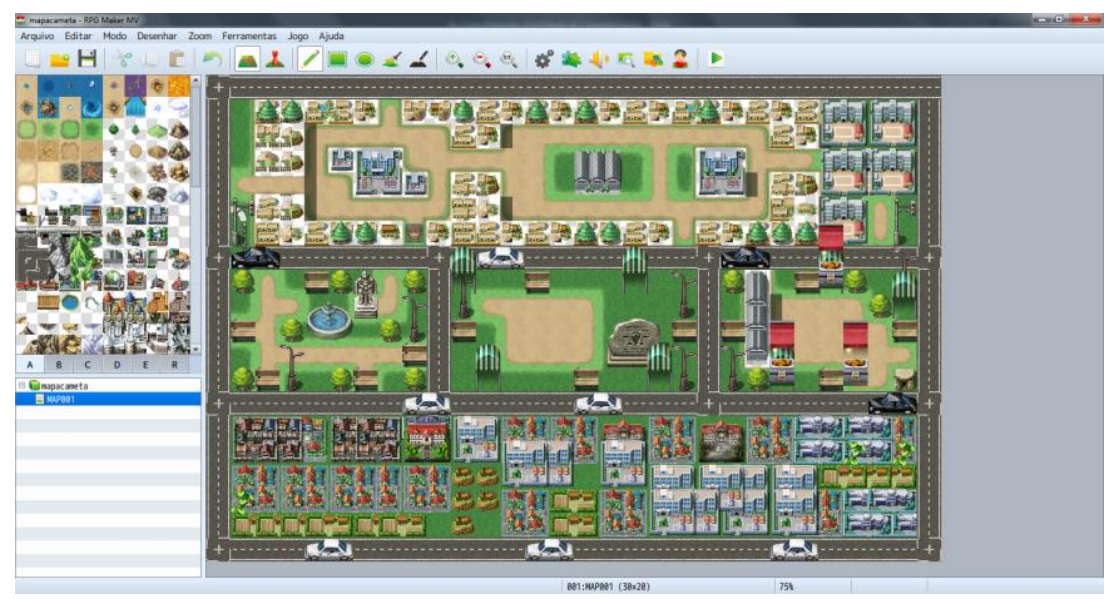

Figura 2. Mapa construído por aluno durante a oficina. 
VIII Congresso Brasileiro de Informática na Educação (CBIE 2019)

Anais do XXV Workshop de Informática na Escola (WIE 2019)

\subsection{Sobre a Etapa IV}

Foi feita uma análise comparativa entre as respostas para averiguar se houve alguma mudança quanto ao conhecimento dos participantes pré e pós-teste.

O primeiro questionamento foi: "Você já assistiu uma aula ministrada com o apoio de Jogos Educativos Digitais?". Destaca-se que no pré-teste, 100\% dos participantes responderam que nunca utilizaram JEDs durante as aulas. No pós-teste, $60 \%$ dos participantes informaram que já haviam utilizado JEDs em sala de aula, enquanto $40 \%$ responderam "NÃO".

Para o segundo questionamento: "Quais são as vantagens dessa abordagem em relação ao ensino tradicional (aula teórica expositiva)?”, 60\% dos participantes descreveram suas experiências. Segundo um deles, "uma das vantagens é prender a atenção do aluno e fazê-lo trabalhar de acordo com o que foi aprendido" e que o uso de JEDS é "uma boa oportunidade para colocar em prática os conhecimentos" relacionados à cartografia. Essas afirmações são equivalentes as informadas pelos docentes que participaram da Etapa I, demonstrando que tanto os docentes quanto os discentes concordam que os JEDs podem tornar as aulas mais atrativas e envolventes, e também, ajudam a fixar os conceitos vistos em sala de aula.

No terceiro questionamento: “Qual a sua percepção de aprendizagem em relação à Geografia Urbana?”, haviam 4 (quatro) alternativas, sendo: Insuficiente, Regular, Boa e Excelente. No pré-teste, todo o grupo, ou seja $100 \%$, se define como possuindo uma percepção "Regular" de aprendizagem em relação ao tema. Já no pós-teste, $80 \%$ disseram possuir percepção "Boa", enquanto $20 \%$ se manteve como "Regular".

O quarto questionamento está relacionado ao tema abordado. Nele pergunta-se: "Sobre o tema urbanização, é INCORRETO afirmar que:". Esta pergunta continha 5 (cinco) alternativas, indo de "A" até "E", sendo que apenas uma das opções define a alternativa correta. No pré-teste, $80 \%$ dos participantes responderam corretamente a essa alternativa, demonstrando possuir um conhecimento mínimo sobre o tema. No pós-teste, apenas $60 \%$ dos participantes assinalaram alternativa corretamente. Nota-se que houve uma pequena redução da percentagem de acertos. Acredita-se que o motivo dessa redução, que representa o erro de 1 (um) aluno, tenha sido pelo fato do mesmo acreditar que tinha errado no pré-teste e tentado responder de outra forma no pós-teste.

No quinto questionamento, perguntou-se: "Segundo Roberto Lobato Correa, considera-se cidade como:". Esta pergunta continha 5 (cinco) alternativas, indo de "A" até "E", sendo que uma das opções define a alternativa correta. No pré-teste apenas $40 \%$ dos participantes responderam corretamente a esta alternativa. No pós-teste, o número de acertos subiu para $100 \%$, demonstrando assim que os participantes estavam atentos à explicação.

O sexto questionamento foi aberto, ou seja, os participantes deveriam descrever com suas próprias palavras e conhecimento prévio sobre "Quais os serviços urbanos que você identifica na cidade de Cametá?".

Suas respostas são apresentadas no Quadro 2. Observa-se que tanto no pré-teste quanto no pós-teste há uma outra problemática quanto a este tema. Os participantes conhecem os serviços que são oferecidos, mas, no entanto, não os sabem nomear corretamente. 
VIII Congresso Brasileiro de Informática na Educação (CBIE 2019)

Anais do XXV Workshop de Informática na Escola (WIE 2019)

Quadro 2. Serviços urbanos oferecidos na cidade de Cametá.

\begin{tabular}{l|l}
\hline \multicolumn{1}{c|}{ Pré-teste } & \multicolumn{1}{c}{ Pós-teste } \\
\hline $\begin{array}{l}\text { Comércios, serviços públicos oferecidos somente } \\
\text { na cidade, Bancos, espaços de lazer como praça. }\end{array}$ & $\begin{array}{l}\text { Serviços públicos como hospitais, fórum, } \\
\text { prefeitura, também comércios }\end{array}$ \\
\hline $\begin{array}{l}\text { Energia elétrica, água encanada, saneamento } \\
\text { básico }\end{array}$ & $\begin{array}{l}\text { Saneamento básico, iluminação pública, água } \\
\text { encanada, limpeza, energia elétrica }\end{array}$ \\
\hline Energia elétrica, água encanada, etc ... & Iluminação pública, sinalização \\
\hline Energia, iluminação pública, coleta de lixo & Iluminação, energia, limpeza, coleta de lixo \\
\hline $\begin{array}{l}\text { Saneamento básico, água encanada, energia } \\
\text { elétrica, iluminação pública, mercado livre }\end{array}$ & Iluminação, limpeza, educação, saneamento \\
\hline
\end{tabular}

\subsection{Sobre a Etapa V}

Nesta subseção descreve-se as experiências dos docentes na aplicação desta proposta. Segundo eles, a proposta é interessante e enriquecedora, uma vez que, possibilita aos alunos aplicarem na prática o que aprenderam na teoria. Também, por ser uma maneira de manter a atenção, desperta o interesse, pois mistura o conteúdo com tecnologia, fazendo com que as crianças possam interagir na sala - ao mesmo tempo em que torna o aprendizado muito mais significativo. Além disso, promove a interação aluno-professoraluno, bem como torna a aula lúdica e prazerosa para o discente, além de estar inserida muitas vezes na realidade do aluno no que concerne a inserção da tecnologia da informação, tão presente no cotidiano de muitas crianças, adolescentes e jovens.

Entretanto, eles afirmam que a falta de infraestrutura nas escolas dificulta a aplicação desta proposta e, consequentemente, privam a oportunidade de os alunos poderem interagir com esse tipo de tecnologia em sala de aula. Eles também apresentam alguns pontos de melhoria, sendo: investir mais em professores capacitados e a criação de uma cartilha contendo todos os recursos oferecidos pela ferramenta.

Para a primeira sugestão, a própria proposta já é uma iniciativa para que os docentes busquem capacitação nesta tecnologia no contexto da UFPA Campus Cametá. Já para a segunda sugestão, um dos componentes da proposta contempla um manual de uso, bem como de instalação, servindo de base para que os docentes sejam capazes de utilizar a ferramenta RPG Maker.

\section{Conclusões}

O principal resultado obtido neste trabalho foi a definição de uma proposta para o ensino cartográfico através de jogos educativos digitais, na qual estabeleceu-se como público-alvo os docentes de Geografia do Ensino Fundamental II. O teste de aplicação mostrou que o RPGMaker possui potencial pedagógico para apoiar o ensino de Geografia. Os alunos puderam aplicar, de forma prática, conceitos inerentes à alfabetização cartográfica, conteúdo-alvo desta proposta. Nenhum destes avaliadores havia utilizado JEDs em sala de aula e, ao final dos testes, $60 \%$ considerou que sua percepção de aprendizagem em relação à Geografia Urbana mudou de regular para boa.

Espera-se que esses resultados sirvam como base para novas pesquisas nas áreas de Jogos Educativos Digitais. Como trabalhos futuros, propõe-se o aprofundamento dos 
VIII Congresso Brasileiro de Informática na Educação (CBIE 2019)

Anais do XXV Workshop de Informática na Escola (WIE 2019)

estudos na utilização de JEDs como ferramenta no processo de ensino-aprendizagem, a fim de identificar novas práticas de ensino e manter esta proposta atualizada, para que, se possa cada vez mais incentivar os profissionais da área educacional a utilizar novas tecnologias em sala de aula. Assim, esses profissionais poderão tornar suas aulas mais atrativas e engajar seus aprendizes na busca por novos conhecimentos.

Adicionalmente, almeja-se buscar uma alternativa open source para a ferramenta RPG Maker. Deseja-se também trabalhar dispositivos móveis, uma vez que, a grande dificuldade apontada pelos avaliadores é a falta de laboratórios de informática para exploração dessas metodologias. Nesse sentido, observa-se que, atualmente, a grande maioria dos alunos possuem smartphones.

\section{Referências}

Aragão, V., Dias, S. e Fernandes, S. (2016). Criação de games na escola: uma experiência de interação, programação e ludicidade. Em Anais do Congresso Brasileiro de Informática na Educação (CBIE 2016), páginas 375-378.

Easterbrook, S., Singer, J., Storey, M-A. and Damian, D. (2007). Selecting Empirical Methods for Software Engineering Research. In Guide to Advanced Empirical Software Engineering, Chap. 11. Springer.

Fernandes, K., Aranha, E. e Lucena, M. (2018). Estratégias para Elaboração de Game Design de Jogos Digitais Educativos: uma Revisão Sistemática. Em Anais do Simpósio Brasileiro de Informática na Educação (SBIE 2018), páginas 585-594.

Filho, C., Dominguez, A., Costa F., Oliveira, P. (2015). Um Jogo Digital Baseado no Construcionismo. Em Revista Brasileira de Informática na Educação (RBIE), páginas 175-189.

Gaite, M. (1995). Juegos y tecnicas de simulacion. In: Enseñar Geografía de la teoría a la practica. Madrid: Editorial Sintesis.

MEC (2018) "Base Nacional Comum Curricular", http://basenacionalcomum.mec.gov.br/wp-content/uploads/2018/02/bncc-20dezsite.pdf, Junho.

Neto, S., Santos, H., Souza, A. e Santos, W. (2013). Jogos Educacionais como Ferramenta de Auxílio em Sala de Aula. Em Anais do Workshop de Informática na Escola (WIE 2013), páginas 130-139.

Papert, S. (2008) "A Máquina das Crianças: Repensando a Escola na Era da Informática”, Em: Artes Médicas, Porto Alegre.

Paula, T., Souza, E., Silva, T., Silva, D. e Ribeiro, M. (2015). Proposta educativa utilizando o jogo RPG Maker. Em HOLOS, páginas 98-112.

Rosa, M. e Maltempi, M. (2003) "RPG Maker: uma proposta para unir jogo, informática e educação matemática”, http://tecmat.pbworks.com/w/page/20359578/Rosa, Junho.

Santos, C., Pedrotti, A., Matos, A. e Santana, A. (2011). A Cartografia e o ensino da Geografia. Em Revista Geográfica de América Central, páginas 1-15.

Sousa, L. e Serafim, M. (2016). Utilizando o Software RPG Maker VX ACE nas aulas de História. Em Congresso Nacional de Educação (CONEDU), páginas 1-12. 